\title{
Thematic analysis of aid workers' stressors and coping strategies: work, psychological, lifestyle and social dimensions
}

\author{
Tarli K. H. Young ${ }^{1 *}$ D, Kenneth I. Pakenham ${ }^{1}$ and Michael F. Norwood ${ }^{2}$
}

\begin{abstract}
Aid workers experience elevated levels of stress which has a detrimental impact on individuals, organisations and the aid sector; however, there is limited qualitative research capturing aid worker's views on stressors and coping strategies. This study used thematic analysis to examine aid workers' views on three research questions: their most common stressors, effective coping strategies and ineffective coping strategies. The study involved a wide range of aid workers $(N=218)$ living in 63 countries, including previously under-researched groups such as development professionals and national workers. Four overarching themes emerged across the three research questions: Work, Psychological, Lifestyle and Social Connection. The most common stressors were work-based issues such as workload, managers and colleagues. Key effective coping strategies were social connections and lifestyle activities such as exercise and hobbies. Ineffective strategies were lifestyle activities such as alcohol and unhealthy eating, and workbased strategies such as working harder. Investigation of aid workers' views through a qualitative approach rather than quantitative scales yielded important new insights such as the high prevalence of work and team stressors, infrequent mention of trauma as a stressor, the important role of psychological support, the importance of meaningful work and the observation that coping mechanisms can be both effective and ineffective depending on context. We used additional quantitative analysis to identify many differences between national and international workers but few between humanitarian and development professionals. Regarding theoretical implications, coping strategies were effectively mapped on to the psychological flexibility framework, which underpins acceptance and commitment therapy. We also use the findings to inform practical stress reduction recommendations at the individual, organisational and sector levels. By giving a voice to aid workers, this research extends our understanding of stress and coping within the aid sector, with the potential to enhance aid worker wellbeing and the delivery of aid.
\end{abstract}

Keywords: Aid workers, Humanitarian, Development, Stressors, Coping strategies, Qualitative, Thematic analysis, Mental health, Interventions, Stress management

Aid workers undertake valuable work and include professionals working on humanitarian missions in conflicts and disasters, and those engaged in development cooperation aimed at long-term economic, environmental, social and political improvements in developing countries (Alonso and Glennie 2015). Aid work is associated with high levels of stress which are well documented in prior quantitative studies using validated scales (e.g. Holtz et al. 2002) and frequency ratings of pre-selected stressors (e.g. Ager et al.

\footnotetext{
*Correspondence: t.young@uq.edu.au

'School of Psychology, The University of Queensland, St Lucia, QLD 4072, Australia

Full list of author information is available at the end of the article
}

2012). Existing research provides an indication of stress prevalence but does not fully capture aid workers' personal views and little is known about the ways in which aid workers themselves experience stress and actively cope on the job. In addition, international humanitarian workers have been widely studied at the expense of development professionals and national aid workers. This is problematic as these groups represent a large portion of aid workers. For example, national workers account for as much as $90 \%$ of all aid workers (Stoddard et al. 2009). Before effective interventions can be designed to help aid workers, we first need to understand the lived experiences of all types of aid workers. 
Capturing aid workers' views can build a fuller and more nuanced understanding of their lived experiences concerning stress. This can enhance the relevance of stress reduction trainings and interventions by contextualising them for the needs of the specific population. Delineating common stressors and helpful coping mechanisms can also normalise stress in the aid sector while providing guidance on coping strategies that other aid workers find effective. Thus, the current study aims to explore aid workers' views on their key stressors and coping strategies using a qualitative methodology. Qualitative research results in data that are not in the form of numbers (Punch 2013) and can build knowledge on complex human experiences (Maudsley 2011). Yet, there are few qualitative studies on aid worker stressors.

\section{Aid worker stressors}

Stress emerges when a person judges personal demands as exceeding their available coping resources (Monat and Lazarus 1991). A stressor is the trigger to this process. There has been increased importance placed on aid worker stress due to the effects at the individual, organisational and sector levels. At the individual level, stress can lead to poor mental health, burnout and posttraumatic reactions (Cardozo and Salama 2002; Eriksson et al. 2009). Organisational costs in the aid sector include team conflicts and staff attrition (Eriksson et al. 2009) which can cause a loss of institutional knowledge, efficiency and capacity (Clarke and Ramalingam 2008). Aid worker stress also impacts the wider aid sector and aid delivery. It is often assumed that the key limiting factor to aid delivery is a lack of funding, but studies have indicated that key barriers are human factors such as poor coordination and leadership (Taylor et al. 2012). Effective aid relies heavily on aid workers and investment in people is argued to be one of the key ways to improve aid delivery (Webster and Walker 2009). Thus, an enhanced understanding of aid worker stressors and coping strategies is important to prevention and mitigation at the individual, organisational and sectoral levels.

Literature reviews on aid worker stress have identified keys stressor categories including traumatic events, living conditions, organisational difficulties and existential challenges such as ethical dilemmas and external criticisms (Cardozo and Salama 2002; Eriksson et al. 2009). Each of these stressor categories is discussed briefly below.

Traumatic stressors involve exposure to traumatic events such as violence. Risks of traumatic events in the aid sector have intensified over the last decade as aid workers are increasingly seen as legitimate targets for robbery, extortion and brutality (Stoddard et al. 2009). However, while some aid workers face considerable physical danger, the stress caused by trauma is often not as prevalent as chronic stressors. For example, in a quantitative study of national aid workers in Northern Uganda, Ager et al. (2012) found that, unlike exposure to traumatic events, exposure to chronic stress was a predictor of depressive symptoms, anxiety and burnout. So it is important to note that chronic everyday stressors can erode mental health resources in aid workers, including those working in high-risk situations (Eriksson et al. 2009).

Existing research suggests aid workers are challenged by chronic work and environmental stressors. For example, Curling and Simmons (2010) summarised a survey of aid workers in a large international organisation which asked participants to rate the prevalence of 11 common stressors. The highest rated stressor was workload, including responses from staff working in emergency stations. Past research using secondary data has noted additional organisational stressors such as excessive bureaucracy, poor management, team conflict, inadequate funding and personnel shortages (Ehrenreich and Elliott 2004). The same research also identified common living condition stressors such as unreliable communications, uncertain security situations, corruption, health concerns and unreliable resources (e.g. electricity and water) (Ehrenreich and Elliott 2004). These findings are important because, while aid workers are often aware of traumatic risks, few expect to be so infuriated by organisational challenges and daily hassles (McKay 2007).

Existential stress in aid work can evoke feelings of helplessness in the face of overwhelming need (Eriksson et al. 2009). Connected to this are the feelings of being unable to significantly help aid recipients (Comoretto et al. 2015), difficulties choosing between different recipients and anger from some beneficiaries (Ehrenreich and Elliott 2004). Thus, aid work can challenge or shatter the fundamental ideals, beliefs and sense of purpose of aid workers (McKay 2007).

While there are many enlightening studies on aid worker stressors, an important research approach which has not yet been undertaken is research which outlines the views of aid workers themselves. Prior important research on aid worker stressors uses quantitative scales (e.g. Holtz et al. 2002; Barbara Lopes Cardozo et al. 2013), or asks participants to rate the prevalence or frequency of pre-determined stressors and coping strategies (Ager et al. 2012; Curling and Simmons 2010). The advantage of these approaches is that they indicate levels of stress and the perceived effects of specific stressors. The disadvantage is that by limiting the range of stressors presented, the studies do not always fully capture what aid workers themselves find stressful. Thus, a key aim of this study is to extend on the existing work to further investigate aid workers' views on stressors. This is important to inform effective stress reduction 
interventions; ensuring they are tailored to the needs of aid workers.

Existing research on aid worker stressors also omits large sections of the population. Recent work focuses on international workers (e.g. Cunningham and Sesay 2017; Gritti 2015) despite national staff contributing about $90 \%$ of the humanitarian workforce and often having direct exposure to humanitarian emergencies (Porter and Emmens 2009; Stoddard et al. 2009). In addition, there is a limited focus on development workers, with most studies focused on humanitarian workers (e.g. Blanchetiere 2006; Connorton et al. 2012). While development workers often operate in less hazardous circumstances, they still face chronic work and psychological stressors which are suggested to have greater impacts on mental health than traumatic stressors (Fawcett 2003).

\section{Coping strategies of aid workers}

An important corollary to understanding aid worker stressors is building knowledge of the coping strategies they use to manage stress. This information can assist aid workers to identify effective strategies and inform stress reduction interventions. There are currently no published qualitative studies, and only a few quantitative studies have investigated aid worker coping strategies. Similar to the work on stressors, existing quantitative studies on coping strategies asked aid workers to rate their reliance on pre-determined items, with strategies often categorised into 'negative' and 'positive' (Blanchetiere 2006; Curling and Simmons 2010). This provides useful information on the prevalence of coping strategies, but quantitative research tends to limit respondents to pre-determined responses. In addition, the categorisation of coping strategies into negative and positive does not align well with stress and coping theory, which proposes that the workability of a coping strategy depends on the immediate context and, therefore, no coping strategy is 'adaptive' or maladaptive' in an absolute sense (Lazarus and Folkman 1984). As with the experiences of stressors, qualitative research is required to understand the full range of coping strategies used by aid workers and to understand their own views on the workability of commonly used strategies.

\section{The present study}

The current study aims to build on existing literature by outlining the views of aid workers' regarding stressors and coping strategies. A qualitative approach is used to elicit aid workers' perspectives without confining them to pre-selected responses. Qualitative data which is not in the form of numbers (Punch 2013) can enhance understanding of complex human experiences (Maudsley 2011). This approach allows aid workers to speak for themselves, thereby providing further insights into their lived experiences. This qualitative approach is supplemented by quantitative analyses which compare the experiences of different sub-groups of aid workers.

Importantly, the current study gathers views from a broad range of aid workers, including development and national workers who are commonly under-researched. An enhanced understanding of a wide range of aid workers' stressors and effective coping strategies is important for informing responses to stress at the levels of individuals, organisations and the broader aid sector. For individual aid workers, findings from the present research can be used to normalise stress and disseminate information on the range of commonly used coping styles. Organisations can use aid worker views to improve structures and staff support. At the sector level, results can inform staff-care resources and interventions to reduce staff stress. Given the importance of aid workers to the sector, efforts to reduce staff stress can have flow-on benefits for the delivery of aid.

\section{Methods}

This study used a cross-sectional online survey methodology. The qualitative questions for this study were included in a large mixed methods survey and quantitative results are discussed elsewhere (Blinded Manuscript). We used inductive thematic analysis (Braun and Clarke 2012) to build an understanding of aid worker's views on stressors and coping strategies.

\section{Participants}

Participants were aid workers aged over 18 years of age, with fluency in English (as the survey was provided in the English language). They were also required to have a minimum of 3 months' work in the aid sector to ensure sufficient exposure to aid work (as per Ager et al. 2012). Aid workers were recruited online through aid worker websites, forums, social media and personal networks. We used a snowballing approach such that existing participants were encouraged to share the survey. We targeted a wide range of aid workers including previously overlooked groups such as national aid workers, development personnel and a wide range of organisations. The survey was voluntary, and no incentives were offered.

There were 218 respondents to the optional open-ended questions. The majority were female (73\%, males $27 \%)$ and the mean age was 37.38 years $(S D=9.18$; range $=19$ to 63$)$. Participants were living in 63 countries and reported 45 nationalities. They had been aid workers for an average of 8.98 years $(S D=7.48$; range $\leq 1$ to 36 years). National workers comprised 22\% of the population, $77 \%$ were international ( $1 \%$ selected 'other'), while $55 \%$ were humanitarian workers, and $35 \%$ were development workers ( $10 \%$ selected 'other'). A total of 29 participants 
were excluded before starting the survey, either for not providing consent (5 participants), never having worked as an aid worker (18) or having less than 3 months' experience (6).

\section{Procedure}

Online announcements of the research provided study information and a URL link which directed interested participants to the 10-20 min survey hosted on Qualtrics (2017). The qualitative component of the survey included open-ended questions on stressors and coping strategies. Demographics information was also obtained. This study was approved by The University of Queensland, School of Psychology Ethics Committee.

\section{Measures}

\section{Socio-demographics}

Information on the following was obtained: age, gender, years worked, international or national worker and humanitarian assistance or development cooperation work. Further demographics were measured as part of a wider questionnaire which is available upon request.

\section{Open-ended questions}

Participants were invited to respond to the following three open-ended questions on stressors and coping strategies with no word limit: What are your top 3 stressors in your role as an aid worker? What are your top 3 most effective strategies you use to cope with stress related to being an aid worker? What are your top 3 least effective coping strategies?

\section{Analysis}

Responses to the open-ended questions were investigated with thematic analysis, using the process recommended by Braun and Clarke (2012). We utilised an inductive method to analysis in that we did not fit the data to existing theory, but took a 'bottom-up' approach and let the data drive the themes. This implies an experiential orientation and essentialist framework, in that it 'gives voice' to aid workers' experiences reported in the data (Braun and Clarke 2012).

The procedure provided by Braun and Clarke (2012) details six steps of analysis which were followed by the first author, a female psychology researcher with 8 years' experience in the aid sector. The process began with familiarisation of the data followed by the development of initial codes to identify meaningful elements in the data. Extracts from the data were coded by the first author using Dedoose (Dedoose Version 8.0.35 2018), an online software for qualitative analysis. In step three, the codes were sorted into overarching themes and sub-themes which explained large sections of the data. Themes were identified at the semantic or explicit level (Boyatzis
1998) due to the brevity of responses. Themes were reviewed and refined in step four, then defined, named and analysed in step five. In the final stage, examples of transcript quotes were chosen to illustrate the themes.

A validity check was conducted through the use of a co-rater to provide multiple perspectives (Fereday and Muir-Cochrane 2006). The second coder was the third author, a male psychology researcher with qualitative research experience but without specific subject matter expertise on aid workers. The second coder independently followed the same six steps outlined above for $20 \%$ of the data. The two coders then discussed their independent findings, which led to agreement on results and the identification of four overarching themes and a number of sub-themes which are presented below. Data was also analysed across key demographic groups (gender, national/international workers and development/humanitarian workers) using chi-squared analysis to identify significant group differences.

\section{Results}

Thematic analysis of responses to the three open-ended questions revealed 4 broad themes and 19 sub-themes, representing 106 codes used 1805 times. The four overarching themes included Work, Psychological, Lifestyle and Social Connection. While there is clear overlap between themes and across the research questions, for clarity, the results below address the three research questions separately and summarise themes, sub-themes and codes pertaining to each. While it is less common for thematic analyses to present codes, we have included this data due to the brevity of survey responses, which led to codes being a meaningful representation of participants' answers. Example extracts from participants are provided in quotations along with their nationality, gender and age in brackets. These extract quotes represent the participants' full, verbatim response to that question and retain spelling and grammatical issues.

\section{Stressors}

Respondents identified a wide range of stressors which we analysed using 8 sub-themes and 46 codes applied 725 times (summarised in Table 1). The sub-themes were grouped under the four overarching themes of Work, Psychological, Lifestyle and Social Connection.

\section{Work stressors}

Work stressors were the most prevalent, both in numbers of different stressors identified and in the frequency of responses. Work stressors were grouped under three sub-themes: 'Working with others', 'Organisational stressors' and 'Work conditions'. Of these, 'Working with others' was the most prevalent. 
Table 1 Stressor code and sub-theme frequency grouped by four overarching themes

\begin{tabular}{|c|c|c|c|c|c|c|c|}
\hline Stressors & & & & & & & \\
\hline Work & 476 & Psychological & 139 & Lifestyle & 74 & Social connection & 36 \\
\hline Working with others & 230 & $\begin{array}{l}\text { Suffering of others and inability } \\
\text { to Help }\end{array}$ & 110 & $\begin{array}{l}\text { Physical health and } \\
\text { safety }\end{array}$ & 48 & Personal relationships & 36 \\
\hline Colleagues & 56 & Lack of impact & 29 & Security concerns & 31 & Separation from loved ones & 17 \\
\hline Managers & 45 & Lack of funding & 26 & Traumatic events & 8 & Loneliness & 14 \\
\hline Unrealistic expectations from others & 37 & Suffering of others & 22 & Health issues & 5 & Lack of intimacy & 5 \\
\hline Donors & 18 & Feeling powerless & 12 & Security restrictions & 4 & & \\
\hline Staff integrity and commitment & 17 & Gap between values and actions & 11 & Living conditions & 26 & & \\
\hline Staff capacity & 12 & Self-doubt & 10 & $\begin{array}{l}\text { Access to personal } \\
\text { resources }\end{array}$ & 10 & & \\
\hline Communication issues & 9 & Unfair systems & 29 & $\begin{array}{l}\text { Difficult living } \\
\text { conditions }\end{array}$ & 7 & & \\
\hline Recipients & 9 & Corruption & 9 & Relocations & 5 & & \\
\hline Managing others & 8 & Lack of recipient focus & 8 & Cultural differences & 4 & & \\
\hline Organisational politics & 8 & Aid system & 6 & & & & \\
\hline Local government & 6 & Inequity & 6 & & & & \\
\hline Local partners & 5 & & & & & & \\
\hline Organisational & 184 & & & & & & \\
\hline Workload & 59 & & & & & & \\
\hline Organisational structures and systems & 28 & & & & & & \\
\hline Bureaucracy & 25 & & & & & & \\
\hline Poor organisational support & 24 & & & & & & \\
\hline Deadlines and time shortage & 21 & & & & & & \\
\hline Large job roles & 6 & & & & & & \\
\hline Lack of recognition & 4 & & & & & & \\
\hline Poor work practices & 17 & & & & & & \\
\hline Work conditions & 62 & & & & & & \\
\hline Work-life balance & 28 & & & & & & \\
\hline Job security & 12 & & & & & & \\
\hline Low wages and financial insecurity & 10 & & & & & & \\
\hline Excessive travel & 7 & & & & & & \\
\hline Sexism & 5 & & & & & & \\
\hline
\end{tabular}

$N=218$. Each participant's response was coded into any theme they evoked and could include multiple codes from the same sub-theme. Thus, themes overlap, and a participant may be represented multiple times within a code, sub-theme or overarching theme

\section{Working with others}

The sub-theme of 'Working with others' was the most frequently reported stressors, attracting 230 uses. Respondents frequently cited issues with "Colleagues" (German female, 38) indicating frustration with "Workmates" (Ugandan female, 26) and "Competition instead of team work” (Italian Female, 35). 'Colleagues' was the second most frequent stressor overall, and the team environment in general appeared to be a key source of stress for aid worker respondents. This may be common in most workplaces but seemed to be exacerbated by perceptions that colleagues were incompetent or uncommitted to aid work, e.g. "Lack of competency in coworkers" (Venezuelan male, 30), the "Abilities and attitudes of some colleagues" (Australian female, 40) and "Working with people who do not care about the job" (Italian female, 35). This frustration seemed to be linked with aid workers' desire to have a meaningful impact.

Another commonly cited issue was 'Difficult supervisors' (Kenyan female, 43), with one respondent explaining '....poor management can disrupt the mission so powerfully and there's usually not a clear complaints and feedback mechanism to ensure you feel protected or heard.' (American female, 59). Poor management was the third most frequent stressor overall and issues with managers often centred on them being inept or unjust, 
e.g. 'Incompetent, unfair and authoritative type of bosses' (Japanese female, 33).

External stakeholders were also noted as a source of stress. Respondents identified issues with donors and government partners such as, 'Unrealistic donor expectations' (American female, 29) and 'Difficult relationship with local government workers' (Mongolian female, 32). Respondents frequently cited stress caused by '...unrealistic demands' (German male, 48), particularly, 'Donors expectations and distance from real issues; (Egyptian male, 57). Interestingly, other external sources of stress were the recipients and organisations that aid workers were seeking to help, e.g. 'relationship with community (French female, 28) and ;Ensuring that funds are well spend by partners' (Nepalese male, 60). Stress caused by working with others connected to a broader sentiment throughout the data; that helping others was a frustrating and complex undertaking.

\section{Organisational stressors}

Organisational systems, structures and demands were noted as a key source of stress. This included 'Work load' (Ugandan female, 26), which was the most common stressor identified by respondents overall, e.g. 'Not feeling like you can have time out from the intensity of the work' (Australian female, 37). Closely connected to workload were other key organisational issues of 'Unreasonably short deadlines' (British male, 47).

A related issue was the lack of organisational support, e.g., 'Inadequate support from regional or headquarter offices' (American female, 41). Lack of organisational support connected to issues around poor organisational structure and systems, e.g. 'Hierarchical structure of organizations; (Nepalese male, 38) and 'lack of strategy/ planning inside my organization' (French female, 28). Bureaucracy was frequently cited stressor, e.g. 'Unsound polices and complicated system' (Burmese female, 37), and some respondents noted a '...disconnect between bureaucracy and our purpose' (American female, 31). Again, this linked to the broader sentiment of a frustrated desire to undertake meaningful work. This is further highlighted by respondents citing stress from, 'Projects being implemented badly' (Irish male, 40) and 'spending money even if it does not make sense' (American female, 33).

\section{Work conditions}

Organisational stressors seemed to be exacerbated by poor working conditions, e.g. 'Job insecurity (contractual nature of this field)' (Canadian female, 40), and 'Low wages' (American female, 30). Respondents also noted stress caused by travel which separated them from their home life, e.g. 'Being away from my family for a long time due to work' (Kenyan female, 30). This was connected to the broader issue of 'Work/life balance' (Canadian female, 35) which was a commonly noted stressor. Several female respondents also mentioned issues of sexism such as, 'Sexism and sexist men in the aid field' (American female, 49).

\section{Psychological and existential stressors}

Psychological and existential stressors were placed under the sub-themes of 'Suffering of others and an inability to help' and 'Unfair systems'.

\section{Suffering of others and an inability to help}

Participants noted stress caused by 'Seeing suffering' (American Female, 29) and 'Loss of human life' (Australian Female, 37). Dissatisfaction or doubt regarding the impact of aid work was exemplified in statements such as, 'Feeling that we are not making a lasting impact' (Italian female, 34) and 'Feeling like no matter how hard you work you're not making a difference' (Australian female, 37). We noted that many of these statements referred to 'feelings' and represented a strong but frustrated desire to help others. For example, one participant noted their 'Sense of helplessness and ineffectiveness to make a dent in an issue' (Sri Lankan female, 35). Other's noted their perceived powerlessness or self-doubt in the face of suffering such as, 'Feeling impotent/irrelevant in my work' (German male, 32) and, 'Feeling powerless in the face of immense crises' (American female, 29). Taken together, these stressors indicate thwarted attempts to help others. This was connected to feeling limited by a lack of resources, e.g. 'Understanding the need but knowing we are limited to respond because of resources and security restrictions' (Australian female, 33).

\section{Unfair systems}

A number of respondents expressed frustration with the aid system in general; specifically with the western agendas of donor agencies which meant aid work was not centred on recipients' needs. This was reflected in responses such as, 'The bureaucracy and the politically motivated action of the Donor organization' (Austrian male, 60). Other respondents noted broader political issues of 'corruption' (British male, 58) and identified issues caused by 'corrupt systems that keep people in relentless poverty no matter what we do' (Australian female, 52).

\section{Lifestyle and location stressors}

Many stressors cited by respondents were specific to the location of aid work in humanitarian or development contexts. Location stressors were grouped under 'Physical health and safety' and 'Living conditions'. 


\section{Physical health and safety}

A key location stressor which affected lifestyle related to safety, e.g. 'Challenging security when working in a difficult circumstances' (Nepalese male, 60) and 'Security restrictions on my movement in country' (American Female, 32). While security concerns were prevalent, far fewer respondents cited traumatic events as a key source of stress. Some noted stress caused by 'Physical danger' (Greek female, 47) but there were only 8 of these types of responses out of 1805 codes uses. This indicates that feelings of insecurity are a more prevalent stressor than traumatic events.

\section{Living conditions}

Some respondents noted the stress of general 'Location hardship' (South African female, 43) and 'Bad living conditions' (Filipino Female, 30) which linked to 'Lack of stress reliever (cultural activity, sports)' (French Female, 42). Others noted specific issues in accessing personal resources such as, 'Not being able to access basics when I need them' (Moldavian female, 31) and 'Power cuts' (Costa Rican female, 38).

\section{Social connection stressors Personal relationships}

Aid work seemed to strain personal relationships and many respondents were troubled by 'Isolation from family and friends' (Canadian female, 40) and 'Being far from the family and kids' (Nepalese male, 38). While many mentioned family and friends specifically, others noted more general feelings of 'Loneliness and lack of social outlet' (Irish female, 28).

\section{Effective coping strategies}

Respondents identified a wide range of effective coping strategies which we analysed using 7 sub-themes and 35 codes (summarised in Table 2).

\section{Effective work-based strategies}

Effective work-based strategies were divided into three sub-themes mirroring work stressors: 'personal organisational,' 'work conditions' and 'working with others'.

\section{Personal organisation}

The most common strategy under 'Personal organisation' was to work less, take breaks and switch off, e.g. 'Time off' (Kenyan female, 30) and 'Taking mandatory breaks from the work' (American female, 29). A number of strategies were specific to personal organisational skills such as planning and problem solving, e.g. 'Make a plan and achieve one by one' (Nepalese male, 43) and 'Finding alternative routs to resolving issues' (Argentinian female, 39).

Table 2 Effective coping strategies code frequency grouped by four overarching themes and seven sub-themes

\begin{tabular}{|c|c|c|c|c|c|c|c|}
\hline \multicolumn{8}{|l|}{ Effective coping strategies } \\
\hline Work & 92 & Psychological & 123 & Lifestyle & 301 & Social connection & 143 \\
\hline Personal organisation & 62 & Practices for mental self-care & 79 & $\begin{array}{l}\text { Helpful activities and } \\
\text { self-care }\end{array}$ & 301 & Support from others & 143 \\
\hline Work less and switch off & 19 & Meditation & 19 & Exercise/ Sport & 94 & $\begin{array}{l}\text { Support from family and } \\
\text { friends }\end{array}$ & 118 \\
\hline Being prepared and organised & 13 & Religion and spiritual practice & 19 & $\begin{array}{l}\text { Hobbies/interests } \\
\text { outside work }\end{array}$ & 62 & Support from colleagues & 25 \\
\hline Good work practices & 13 & Therapy & 12 & Holidays and travel & 34 & & \\
\hline Commitment to work & 9 & Relax & 12 & Work-life balance & 19 & & \\
\hline Analyse and solve problems & 8 & Purpose and goals & 9 & Socialising & 19 & & \\
\hline Working with others & 16 & Self-awareness & 4 & Time for me & 16 & & \\
\hline $\begin{array}{l}\text { Management and organisational } \\
\text { support }\end{array}$ & 7 & Personal growth & 4 & Yoga & 15 & & \\
\hline Contact with recipients & 5 & Cognitive appraisal strategies & 44 & Eating well & 14 & & \\
\hline Delegation & 4 & Humour & 11 & Alcohol & 14 & & \\
\hline Work conditions & 14 & Focus on circle of influence & 10 & Sleep and rest & 14 & & \\
\hline Ensure good conditions & 9 & Acceptance & 6 & & & & \\
\hline \multirow[t]{3}{*}{ Changing jobs/location } & 5 & $\begin{array}{l}\text { Perspective, seeing bigger } \\
\text { picture }\end{array}$ & 6 & & & & \\
\hline & & Stay positive & 6 & & & & \\
\hline & & Ignoring problems & 5 & & & & \\
\hline
\end{tabular}

$N=218$. Each participant's response was coded into any theme they evoked and could include multiple codes from the same sub-theme. Thus, themes overlap, and a participant may be represented multiple times within a code, sub-theme or overarching theme 


\section{Work conditions}

Several individuals sought to ensure good working conditions, mirroring the stressor of poor working conditions. This included strategies such as 'Get well paid work' (Australian female, 55) and 'Flexible job hours' (Canadian female, 35). Sometimes, the strategies involved changing jobs entirely, e.g. 'Get out of situations in work place that are unhealthy and are streaching you confidence and emotional wellbeing' (Australian female, 44).

\section{Working with others}

A few aid workers noted that support from 'understanding management' (Australian male, 43) was important, along with more formal organisational support such as 'Getting necessary security briefings' (Nepalese male, 60). Other participants sought to shape their current role to ensure they were more in contact with recipients to promote meaningful work, e.g., 'Making sure I am in sync with people in the field to make sure what I do is useful' (Serbian female, 27).

\section{Effective psychological strategies}

Psychological strategies fell into two separate subthemes of 'Practices for mental self-care' and 'Cognitive appraisal strategies'.

\section{Practices for mental self-care}

'Practices for mental self-care' focused on mental wellbeing, including self-awareness and personal growth, e.g. 'I strive to be aware of my feelings' (French male, 32) and 'Self improvement' (British male, 24). Connected to these were responses about having a purpose, e.g. 'Taking time to asses what is important to me' (British female, 37) and 'Seeing people in need being helped' (Macedonian female, 36). Other mental self-care strategies were more activity-based with many responses including 'Meditation' (South African female, 43) and 'Relaxation' (Australian male, 53). Several aid workers also noted the importance of their faith with responses such as 'Relationship with God' (Filipino female, 32) and 'Prayer' (Ugandan female, 30). Some found therapy and psychological support was helpful, e.g. 'I talk to counselors when necessary’ (Kenyan female, 43).

\section{Cognitive appraisal strategies}

'Cognitive appraisal strategies' included acceptance, e.g. 'Knowing that I can only try my best' (Australian female, 38) and seeing the bigger picture, e.g. 'Re-framing and getting some perspective over the importance of some tasks' (Czech female, 28). Respondents focused on what they could influence, exemplified by statements such as, 'Work out what you CAN do, what you can't, and don't worry about the latter. Put your efforts into the former' (British male, 47). Aid workers also sought to adopt positive strategies such as, 'Stay positive' (Pakistani female, 28) and identified a 'sense of humor' (Spanish male, 51) as important.

\section{Effective lifestyle strategies}

Lifestyle strategies were the most prevalent effective coping strategies. Responses included a wide range of activities placed under the sub-theme of 'Helpful activities and self-care'.

\section{Helpful activities and self-care}

Participants emphasised the need to have interests and activities outside of work, e.g. 'having a life outside the office' (Filipino female, 26). This seemed a deliberate counterbalance to high workloads and a lack of work-life balance, both identified as key stressors.

Exercise and sports was the second most frequent effective coping strategy overall, e.g. 'Exercise' (Filipino male, 39), 'Exercise every evening' (Ugandan female, 26) and 'Sports and hobbies' (Filipino Female, 37). Several responses specified 'yoga' (Polish female, 31) as helpful. Other common interests included 'Reading' (Burmese female, 37), 'keeping a diary' (British female, 45), 'Watching film and hearing music' (Canadian female, 43) and 'Taking regular breaks, vacations' (American female, 41).

A number of activities focused on having a healthy lifestyle, e.g. 'Diet/healthy eating' (South African female, 43) and 'getting enough sleep' (French female, 33). A differing strategy was 'Alcohol' (Filipino female, 30), although every participant who identified alcohol as effective also identified it as an ineffective strategy. Alcohol use overlapped with socialising and respondents identified, 'Social drinking' (Australian male, 33) and 'Social life' (British female, 63) as important coping strategies. Some respondents identified the need for 'time for me' (Italian female, 39), while others noted the need for balance, e.g. 'Socialising but not too much: making sure to find the balance between spending time with people and not drinking too much or being able to say no if you need alone-time (and setting aside alone time)' (British female, 26).

\section{Effective social connection strategies}

Social connection strategies included one sub-theme labelled 'Support from others'.

\section{Support from others}

Social support and talking with family and friends was the most frequent effective coping strategy. The code was used 118 times, making it the most prevalent code over all 3 research questions. Many participants identified the importance of existing support such as, 'Spent more time with family' (Nepalese male, 38), 'sharing with friends' (Burmese Female, 37) and 'love from family' 
(Kenyan female, 36). Others identified the need to seek new connections, e.g. 'Making new friends and networks' (Nepalese male, 60) and 'Forming bonds with people in the same location' (Moldavian female, 31). Some respondents preferred support from someone outside the aid sector, e.g. 'a spouse outside the aid worker world who bring perspective' (Australian female, 38). But for a sizeable subset of participants, sharing with colleagues was an important strategy, e.g. 'Be open to colleagues and share my problems' (Kenyan female, 30).

\section{Ineffective coping strategies}

Respondents identified many ineffective coping strategies they undertook. These were analysed using 25 codes, applied 421 times (Table 3). There was a smaller range of responses to this question and we created four sub-themes which aligned directly with the four overarching themes of Work, Psychological, Lifestyle and Social Connection.

\section{Ineffective work-based strategies Ineffective work-based strategies}

Working more or harder was the second most frequent ineffective coping strategy, e.g. 'working long hours' (Ethiopian female, 38) and 'Burying mysefl in work' (French Female, 28). Some participants noted fruitless attempts to 'Overwork to drown out stress and frustration' (American female, 31). Others observed that they blurred the lines between work and life, e.g. 'Staying late in the office or checking emails constantly from home or on mobile phone' (French female, 26) and 'Not taking leave' (Kenyan female, 38). Some ineffective work-based strategies were unhelpful habits such as procrastination, e.g. 'delaying the daily tasks, which further bounces back' (Nepalese male, 38). Other respondents cited ineffective organisational support mechanisms such as 'Group debriefs' (Australian female, 59) and 'Talking to supervisors' (Zimbabwean female, 39). Overall, this sub-theme painted a picture of overworked and unsupported aid workers who sometimes responded by working in ways that exacerbated stress.

\section{Ineffective psychological strategies Ineffective psychological strategies}

The most common ineffective psychological strategy was avoidance, exemplified by statements such as 'Ignoring the situation' (Venezuelan male, 26) and 'Not doing anything' (Canadian female, 43). Others took the opposite approach, tending towards rumination, e.g. 'Dwelling on things' (Irish male, 40) or 'Over thinking' (Nepali male, 30). Additional psychological strategies included emotion-based responses such as 'Crying' (Kenyan female, 30) and 'Feeling sad' (British female, 37) or 'Angry outbursts' (Canadian female, 40) and 'Frustration' (British male, 52).

\section{Ineffective lifestyle strategies Unhelpful activities and lack of self-care}

Participants identified many unhelpful activities and habits. The most common of these was 'Alcohol' (Kenyan female, 32), which was also the most frequent ineffective strategy overall. Respondents noted the ineffectiveness of 'Drinking' (Dutch Female, 33) and 'Increased alcohol use'

Table 3 Ineffective coping strategies code frequency grouped by four overarching themes

\begin{tabular}{|c|c|c|c|c|c|c|c|}
\hline Work & & Psychological & & Lifestyle & & Social connection & \\
\hline $\begin{array}{l}\text { Ineffective work-based } \\
\text { strategies }\end{array}$ & 93 & $\begin{array}{l}\text { Ineffective psychological } \\
\text { strategies }\end{array}$ & 73 & $\begin{array}{l}\text { Unhelpful activities and lack } \\
\text { of self-care }\end{array}$ & 177 & $\begin{array}{l}\text { Ineffective social support } \\
\text { strategies }\end{array}$ & 78 \\
\hline Working more or harder & 61 & Avoidance/ignoring issues & 26 & Alcohol & 73 & Isolation & 31 \\
\hline Procrastination & 12 & Getting angry & 22 & Poor diet/over-eating & 28 & Complaining & 23 \\
\hline Taking on everything & 9 & Worry and ruminate & 15 & Watching TV/movies & 14 & Talking to the wrong people & 14 \\
\hline $\begin{array}{l}\text { Poor organisational } \\
\text { support }\end{array}$ & 8 & Crying and feeling sad & 10 & Smoking & 14 & Social withdrawal & 10 \\
\hline \multirow[t]{8}{*}{ Changing jobs } & 3 & & & Poor sleep habits & 10 & & \\
\hline & & & & Social media/internet & 7 & & \\
\hline & & & & Sex & 7 & & \\
\hline & & & & Drugs & 6 & & \\
\hline & & & & Socialising & 6 & & \\
\hline & & & & Not doing self-care & 5 & & \\
\hline & & & & Caffeine & 4 & & \\
\hline & & & & Shopping & 3 & & \\
\hline
\end{tabular}

$N=218$. Each participant's response was coded into any theme they evoked and could include multiple codes from the same sub-theme. Thus, themes overlap, and a participant may be represented multiple times within a code, sub-theme or overarching theme 
(British male, 28) which overlapped with issues of 'Drugs' (Australian male, 53), and 'partying and social life' (Italian female, 39). Other unhelpful substances noted were 'Caffeine' (British female, 32) and 'Smoking' (Nepali male, 38). Many respondents used food as an ineffective strategy noting the problems with 'Stress eating' (Australian female, 36). Others noted poor sleep habits which were evenly split between 'lack of sleep' (Spanish female, 34) and 'Oversleeping' (Canadian female, 51). Aid workers also commented on additional unhelpful activities such as 'Watching TV' (Kenyan female, 30), 'internet' (Canadian male, 50), 'Social media' (Ugandan female, 30) and 'Sex to escape' (Dutch female, 33). Overall, the sub-theme indicated aid workers were well aware of their unhelpful activities but engaged in them nonetheless.

\section{Ineffective social connection strategies Ineffective social support strategies}

Ineffective social support strategies included isolation, e.g. 'Isolating myself sometimes' (Ugandan female, 26) and 'don't look for an help' (Italian female, 39). Connected to this, some aid workers noted they avoided speaking about their problems, e.g. 'Bottling stuff in' (Sri Lankan female, 35). There were a small number who noted issues with talking to the wrong people, e.g. 'speak out about my feelings with colleagues' (Italian female, 36), 'talking to those outside the industry (friends/family)' (British female, 45) and 'talking to friends at home who do not understand the reality on the ground' (Australian female, 37). Some respondents noted they used social support in unhelpful ways such as 'complaining' (Mongolian female, 32) or 'Ranting' (Filipino female, 32). This highlights problems with unhelpful forms of social connection, although the overwhelming focus from participants was on the lack of connection with others.

\section{Sub-themes by demographics}

We analysed the prevalence of themes and sub-themes by key demographic groups including national/international workers, development/humanitarian workers and female/male. Prevalence by group and differences are outlined in Table 4.

There were substantial differences between national and international aid workers. Internationals were coded significantly more often in six out of eight stressor sub-themes. Differences were particularly prominent within the sub-theme of 'Working with others', and specifically in relation to the stressor code of 'Colleagues'. International workers also cited more difficulties within 'Working conditions' with particular issues caused by work-life balance. The sub-theme of 'Physical health and safety' was also noted significantly more often by international workers. In terms of coping strategies, internationals noted the use of
'Helpful activities and self-care' and 'Support from others' more frequently. International workers identified all sub-themes of ineffective coping significantly more frequently.

There were fewer differences between development and humanitarian workers. Humanitarian workers identified more 'Organisational' stressors which seemed to be driven by workload and bureaucracy. Humanitarian workers were also more likely to cite 'Unhelpful activities and lack of self-care' as ineffective coping strategies.

Female aid workers were more likely to identify stressors under the sub-theme of 'Living conditions'. In terms of coping strategies, males were more likely to identify work-based strategies such as 'Personal organisation' and 'Working with others'. Regarding ineffective coping strategies, female respondents more often cited 'Unhelpful activities and lack of self-care'.

\section{Discussion}

Findings of the present study provide insights into aid worker's views and lived experiences; adding depth and nuance to the discussion on aid stressors and coping strategies. Such data can help normalise aid worker's experiences of stress and inform training and intervention responses. As we targeted a wide range of aid workers, the results illuminate differences between sub-groups of aid workers such as international and national workers.

Four overarching themes emerged: Work, Psychological, Lifestyle and Social Connection. Some results aligned with past research, but many new findings emerged. Work stressors were the most frequently reported in this study, and the theme included three times as many responses as the second most frequent theme (Psychological stressors). The prevalence of Work stressors reflects findings from prior research indicating workload is the highest source of stress for aid workers (Curling and Simmons 2010). However, there is little research on team stressors for aid workers, and we found 'Working with others' was the most prevalent stressor sub-theme, including the frequent stressor codes of 'Colleagues' 'Managers and supervisors' and 'Unrealistic expectations from others'. Notably, this finding indicates that many stressors come from within the aid worker's own team.

While work stressors were common with relevant codes used 476 times, effective work-based coping strategies were the least cited by respondents, being noted only 7 times. One possible interpretation of this is that respondents were stressed by work, but did not see helpful support options within their organisations. This finding reflects those of previous research showing poor organisational support for aid worker mental health (Curling and Simmons 2010). This is a key finding as there is a tendency to view aid work as intrinsically 
Table 4 Sub-theme by demographic sub-groups, as a percentage of the number of respondents within the sub-group and chisquare values

\begin{tabular}{|c|c|c|c|c|c|c|c|c|c|}
\hline & Female & Male & $x^{2}$ & Development & Humanitarian & $x^{2}$ & National & International & $x^{2}$ \\
\hline N & 204 & 67 & 271 & 98 & 135 & 233 & 71 & 198 & 269 \\
\hline \multicolumn{10}{|l|}{ Stressors } \\
\hline \multicolumn{10}{|l|}{ Work } \\
\hline Working with others & $45 \%$ & $52 \%$ & 1.81 & $55 \%$ & $43 \%$ & 3.35 & $27 \%$ & $54 \%$ & $15.06^{* * *}$ \\
\hline Organisational & $43 \%$ & $51 \%$ & 1.34 & $36 \%$ & $53 \%$ & $6.52^{*}$ & $34 \%$ & $49 \%$ & $4.56^{*}$ \\
\hline Work conditions & $21 \%$ & $18 \%$ & 0.31 & $22 \%$ & $21 \%$ & 0.10 & $6 \%$ & $26 \%$ & $13.01^{* * *}$ \\
\hline \multicolumn{10}{|l|}{ Psychological } \\
\hline Suffering of others and inability to help & $23 \%$ & $24 \%$ & 0.9 & $28 \%$ & $30 \%$ & 0.22 & $25 \%$ & $30 \%$ & 0.51 \\
\hline Unfair systems & $8 \%$ & $12 \%$ & 0.78 & $14 \%$ & $7 \%$ & 2.91 & $7 \%$ & $10 \%$ & 0.42 \\
\hline \multicolumn{10}{|l|}{ Lifestyle } \\
\hline Living conditions & $11 \%$ & $2 \%$ & $5.607^{*}$ & $8 \%$ & $10 \%$ & 0.32 & $1 \%$ & $11 \%$ & $6.29^{*}$ \\
\hline Physical health and safety & $16 \%$ & $10 \%$ & 1.32 & $14 \%$ & $14 \%$ & 0.00 & $3 \%$ & $19 \%$ & $11.07^{* * *}$ \\
\hline \multicolumn{10}{|l|}{ Social connection } \\
\hline Personal relationships & $9 \%$ & $13 \%$ & 0.92 & $7 \%$ & $13 \%$ & 2.27 & $3 \%$ & $13 \%$ & $5.96^{*}$ \\
\hline \multicolumn{10}{|l|}{ Effective coping } \\
\hline \multicolumn{10}{|l|}{ Effective work-based strategies } \\
\hline Personal organisation & $15 \%$ & $30 \%$ & $7.09^{*}$ & $17 \%$ & $21 \%$ & 0.42 & $25 \%$ & $16 \%$ & 2.92 \\
\hline Working with others & $2 \%$ & $15 \%$ & $17.30^{* * *}$ & $7 \%$ & $4 \%$ & 0.79 & $10 \%$ & $4 \%$ & 4.24 \\
\hline Work conditions & $5 \%$ & $0 \%$ & 3.77 & $4 \%$ & $4 \%$ & 0.02 & $1 \%$ & $5 \%$ & 1.77 \\
\hline \multicolumn{10}{|l|}{ Effective psychological strategies } \\
\hline Practices for mental self-care & $26 \%$ & $21 \%$ & 0.7 & $19 \%$ & $27 \%$ & 2.00 & $20 \%$ & $27 \%$ & 1.39 \\
\hline Cognitive appraisal strategies & $13 \%$ & $12 \%$ & 0.03 & $14 \%$ & $12 \%$ & 0.30 & $10 \%$ & $13 \%$ & 0.52 \\
\hline \multicolumn{10}{|l|}{ Effective lifestyle strategies } \\
\hline Helpful activities and self-care & $58 \%$ & $49 \%$ & 1.51 & $54 \%$ & $61 \%$ & 1.03 & $25 \%$ & $67 \%$ & $36.16^{* * *}$ \\
\hline \multicolumn{10}{|l|}{ Effective social connection strategies } \\
\hline Support from others & $47 \%$ & $39 \%$ & 1.39 & $47 \%$ & $46 \%$ & 0.02 & $20 \%$ & $55 \%$ & $25.58^{* * *}$ \\
\hline \multicolumn{10}{|l|}{ Ineffective Strategies } \\
\hline \multicolumn{10}{|l|}{ Ineffective work strategies } \\
\hline Ineffective work-based strategies & $29 \%$ & $19 \%$ & 2.57 & $28 \%$ & $28 \%$ & 0.01 & $7 \%$ & $34 \%$ & $19.14^{* * *}$ \\
\hline \multicolumn{10}{|l|}{ Ineffective psychological strategies } \\
\hline Ineffective psychological strategies & $21 \%$ & $28 \%$ & 1.52 & $26 \%$ & $24 \%$ & 0.10 & $13 \%$ & $27 \%$ & $5.85^{*}$ \\
\hline \multicolumn{10}{|l|}{ Ineffective lifestyle strategies } \\
\hline Unhelpful activities and lack of self- care & $41 \%$ & $28 \%$ & $5.21^{*}$ & $33 \%$ & $47 \%$ & $5.10^{*}$ & $14 \%$ & $50 \%$ & $27.97^{* * *}$ \\
\hline \multicolumn{10}{|l|}{ Ineffective social connection strategies } \\
\hline Ineffective social support strategies & $25 \%$ & $18 \%$ & 1.25 & $28 \%$ & $23 \%$ & 0.64 & $7 \%$ & $29 \%$ & $13.93^{* * *}$ \\
\hline
\end{tabular}

${ }^{*} p<.05 ;{ }^{* *} p<.01 ;{ }^{* * *} p<.0011$

stressful due to the challenging circumstances in developing countries, but findings from the present study indicate that many of the keys stressors originate from within the organisation and team. This is further exacerbated by the lack of effective support from organisations as perceived by participants.

While security concerns were a prevalent stressor in line with past research (Ehrenreich and Elliott 2004), we noted that trauma was infrequently mentioned (8 instances among 1805 code uses overall). This differs from prior studies which focus on aid worker reactions to trauma (Connorton et al. 2012; Shah et al. 2007) and also from literature reviews which have identified traumatic stress as a prominent concern among aid workers (Cardozo and Salama 2002; Eriksson et al. 2009). In line with this, aid organisations tend to provide support only 
for those staff who have experienced traumatic incidences (Gritti 2015). However, the vast majority of aid workers in the present study did not report trauma as a source of stress. Prior research has employed stressor checklists that have included trauma but omitted some of the more common chronic stressors identified in this study (e.g. 'Colleagues'). The small number of trauma responses in the present study is not an indication of the low impact of trauma. Aid workers experience an elevated risk of trauma (Stoddard et al. 2009) which can have enduring impacts long after other stressors have receded (Eriksson et al. 2012). However, the results of the present study suggest that other stressors are more common and are likely to be detrimental to aid worker wellbeing.

In contrast to prior quantitative research on aid worker coping strategies, the current results indicate a vast array of strategies, including 60 different codes. For example, psychological coping strategies have not received much attention previously but were frequently reported in this study. The theme included 13 codes under 2 sub-themes and suggests that helpful psychological approaches may be effective for aid workers. This result reflects findings from studies using other populations (DeLongis and Holtzman 2005). However, aid organisations seldom target this important set of coping strategies with appropriately tailored psychological support interventions (Curling and Simmons 2010).

Contrary to past aid worker coping research, the current results indicated that some coping strategies were both effective and ineffective. For example, 'Alcohol' was listed as both an ineffective and effective strategy, often by the same respondents (although it was mostly identified as ineffective). Similarly, two seemingly opposite strategies such as 'working less' versus 'working more' were noted as helpful to different people. This differs from past aid worker research which has tended to label coping strategies as either 'positive' or 'negative' (Blanchetiere 2006; Curling and Simmons 2010). While this existing research provides clarity, such labelling involves a subjective judgement by researchers, whereas we found aid worker coping strategies to be more context and person dependent. Our results align with stress and coping theory which proposes that the effectiveness of a coping strategy can only be judged by its outcomes within a given context (Lazarus and Folkman 1984).

'Social support from family and friends' was the most commonly cited coping strategy and the most frequent code overall. This reflects past research which indicates that social support is associated with lower levels of depression, psychological distress and burnout (Lopes Cardozo et al. 2012). Skeoch et al. (2017), this issue) demonstrated that trainee humanitarians identified future colleagues as their most important source of support as opposed to family and friends. Building on this work, results from the present study suggest that aid workers who are currently practising rely more heavily on family and friends, and some even warn against seeking support from colleagues. This highlights a difference between future expectations of humanitarian trainees and real-world strategies of current aid workers.

A key finding which emerged across multiple themes was the importance aid workers placed on meaningful work, and the stress caused by frustrated attempts to work in line with their personal values. This aligns with previous research suggesting that meaningful action is important for aid workers (McKay 2011) who are commonly motivated by the promise of meaningful work (Ager and Iacovou 2014). However, qualitative field accounts have noted that many aid workers become disillusioned and cynical (Pigni 2014). This is problematic as an underlying cause of burnout is an unfulfilled wish to feel one's actions are meaningful (Pines and Keinan 2005). While some staff guidelines note the importance of meaning to aid workers (McKay 2011), there is no published research on the links between meaning and mental health outcomes such as stress. The current results suggest meaning is of central importance to aid workers and this area warrants further research.

When examining demographic differences, the largest difference was between national and international aid workers. Internationals more frequently cited six out of eight stressor sub-themes including difficulties within 'Working conditions' and 'Physical health and safety'. This may be because international workers are less accustomed to local conditions. The finding also supports research suggesting higher stress in international aid workers may be due to them having less social and local support (Connorton et al. 2012).

Female aid workers were more likely to identify stressors under the sub-theme of 'Living conditions'. This aligns with past research suggesting that female aid workers often experience greater stress (Curling and Simmons 2010), due to factors such as discrimination, sexual harassment and security restrictions (Gritti 2015). Female workers were also more likely to cite 'Unhelpful activities and lack of self-care' which seemed to be driven by more problems with 'poor diet or over-eating'.

There were few differences between development and humanitarian workers. Humanitarian workers identified more 'Organisational' stressors such as workload and bureaucracy. They were also more likely to cite 'Unhelpful activities' such as alcohol (supporting Costa et al. 2015). There were no differences between the two groups in terms of physical health and safety as a key stressor, despite the emergency nature of humanitarian work. This may be because humanitarian workers saw security issues as inherent to humanitarian work and 
thus were more able to accept these stressors (Crane et al. 2018). The results indicate that there are few differences between the development and humanitarian workers despite past research focusing predominantly on humanitarian workers.

\section{Theoretical implications}

We further explored the coping strategy results from the present study to determine whether the data could be mapped on to a theoretical framework that could inform interventions for enhancing coping repertoires. As previously mentioned, we did not code the data in line with a theoretical approach. Hence, it was only after the completion of analyses that we re-examined the results to ascertain whether they aligned with existing theoretically informed intervention approaches. Overall, we found that the coping data aligned with the psychological flexibility framework, which informs the empirically supported acceptance and commitment therapy (ACT, Hayes et al. 2011), a recent variant of the well-established cognitive and behaviour therapy.

Psychological flexibility involves the capacity to connect to the present and act in accordance with personal values, even in the presence of unwanted difficult thoughts, emotions and sensations. It has been linked with decreased worksite stress (Bond and Bunce 2000) and reduced burnout (Hayes et al. 2004), and greater well-being in a wide range of populations across numerous cultures (Powers et al. 2009). Psychological flexibility is comprised of six therapeutic processes which align with many of the effective coping strategies identified in this study. Meanwhile, the ineffective coping strategies identified in this study align with the inverse of these processes.

Two closely linked psychological flexibility processes are 'values' and 'committed action'. Together, these refer to taking effective action in the service of personally meaningful values (Luoma et al. 2007). The stressor data from the present study highlight the stress related to thwarted attempts to undertake meaningful work in line with personal values. These include stressors such as dissatisfaction over the impact of aid work and being unable to help the suffering of others. The results also indicate that taking values-based actions was the most common effective coping strategy for respondents. For example, respondents commonly remarked on the importance of their family and friends and took specific actions to increase time with their loved ones. Many respondents deliberately cultivated meaning in their work by ensuring contact with recipients and maintaining their commitment to aid work.

A third psychological flexibility process is 'acceptance' of difficult internal experiences (thoughts, feelings and bodily sensations). Several respondents identified this strategy, stating they accepted events outside of their control and focussed on what they could influence. According to the psychological flexibility framework, acceptance is the antidote to experiential avoidance, which involves avoidance of unwanted thoughts and feelings using strategies such as suppression and distraction (Luoma et al. 2007). Many of the most common ineffective coping strategies in this study involved experiential avoidance such as alcohol use, eating, watching TV and working more to avoid stress.

The psychological flexibility process 'defusion' involves being aware of a thought without acting on its content. Respondents identified effective defusion strategies such as seeing the bigger picture, shifting from negative to positive mental content and mentally focusing on elements of their work that they could influence. This is the opposite of fusion with thoughts, which involves being absorbed in mental activity (Hayes et al. 2006). Fusion was implied in many ineffective coping strategies such as worrying, rumination and getting angry.

The fifth psychological flexibility process is 'contact with the present moment' (i.e. mindfulness) and was implied in some of the respondent's effective strategies such as meditation, relaxing, taking breaks and switching off. The inverse of this process is being absorbed in the past or future and was central to some of the ineffective coping strategies such as worry and rumination.

Contact with the present moment facilitates 'self-as-context', the sixth psychological flexibility process. Self-as-context involves noticing from awareness one's internal experiences (thoughts and feelings) and enables flexible perspective taking as opposed to being attached to mental content such as concepts of self (Fledderus et al. 2012). The self-as-context process was implicated in some effective coping strategies such as getting perspective and seeing the bigger picture.

The psychological flexibility framework appears to have utility in conceptualising the coping strategies used by aid workers. This framework has several advantages. First, it is trans-diagnostic in that it identifies change processes that cut across mental health disorders (Hayes and Hofmann 2017). Second, these processes can be targeted by techniques from a wide range of psychotherapies (Hayes and Hofmann 2017). Third, the psychological flexibility framework informs a well-tested trans-diagnostic intervention approach (ACT) that has been widely used in mental health promotion and prevention in many different settings and cultures (Powers et al. 2009). Thus, the integration of qualitative data from the present study with the psychological flexibility framework can inform interventions for enhancing aid worker wellbeing at the individual, organisational and sector levels.

\section{Practical implications \\ Individual practical implications}

For individual aid workers, stress can lead to poor mental health, burnout and posttraumatic reactions (Cardozo 
and Salama 2002; Eriksson et al. 2009). As a starting point, sharing the common stressors identified in the present study may help normalise the challenges of the sector, particularly with regards to some unexpectedly common stressors such as team dynamics and feeling unable to help others. Sharing common stressors has been beneficial in other sectors including the disclosure of traumatic incidences among health practitioners (Farrington 1995). Many respondents to our survey reported that they wanted to hear more about other aid workers' common stressors to help normalise their experiences. Such normalisation through sharing may be particularly pertinent in the aid sector where stigma often prevents discussion of mental health issues (Fechter 2012).

The study respondents also indicated they wanted to know more about other aid workers' coping mechanisms to expand their coping repertoires. Given this need, it is worth highlighting that social connection was the most prevalent effective coping code overall along with common helpful habits such as exercise, holidays, hobbies, prayer, meditation and socialising. Implied in all these strategies is engagement in actions aligned with personal values. Hence, it is important that aid workers are encouraged to clarify and connect with their personal values, not only at work but also in other life domains. Aid workers should also be supported to act consistently in relation to their personal values. However, given the many documented work-related stressors, this may be challenging at times; hence, other psychological flexibility processes also need to be activated to foster values-based action.

\section{Organisational practical implications}

At the organisational level, the costs of stress include staff attrition (Eriksson et al. 2009) and lost institutional knowledge, efficiency and capacity (Clarke and Ramalingam 2008). Our findings suggest many aid workers see their organisations as a leading cause of stress and simultaneously, do not feel organisational support is effective. The most prevalent stressor identified in this study was workload, which could prompt further consideration around staffing plans and work roles. While additional staff or better organisational support may be costly, it is likely to reduce staff stress, turnover and loss of efficiency in the long-term. Other commonly reported organisational stressors were managers and team dynamics. Effective organisational responses demonstrated in other sectors could be adopted by aid organisations, including management training, regular meetings between managers and staff (Daniels 1990), internal updates and team building (Dyer 2007).

The current results can also inform the types of support that aid organisations provide staff. For example, many aid organisations only provide support for aid workers who have had a traumatic experience (Ehrenreich and Elliott
2004), while the current research indicates that work and psychological stressors are more prevalent. Thus, organisations should provide psychological support and training for aid workers even if they have not experienced a recent trauma. Given that social support was the most prevalent coping strategy, organisations could also do more to help aid workers maintain their support network. This could involve facilitating frequent home visits, supporting the families of aid workers, encouraging social support among colleagues and improving communication channels in remote placements.

\section{Sector-level practical implications}

At the sector-level, stress reduces the effectiveness of aid workers and fundamentally hinders their ability to provide services to aid beneficiaries (Webster and Walker 2009). Thus the wider sector, and donors specifically, should support the mental health of aid workers in order to promote the effective delivery of aid. Donors and their 'unrealistic expectations' were a key stressor for aid workers and respondents suggested that donors were unaware of the effect they had on aid workers. Donors can increase their awareness of the costs of staff stress and seek feedback from aid workers. They can also set priorities around aid worker mental health within projects by including staff care indicators within reporting frameworks.

Within the wider aid sector, there are existing staff care materials (e.g. McKay 2007) but no empirically tested psychological interventions tailored to the needs of aid workers. Future development of such interventions could incorporate the current results by focusing on psychological flexibility skills that are effectively taught through approaches such as ACT (Hayes et al. 2006). Ideally, this type of training will be delivered across the sector (possibly by staff care organisations) to reach a wide range of aid workers and help mitigate problems of inconsistent organisational support. Sector-wide support for aid workers is important given that there is currently little support for aid workers who face a large variety of stressors.

\section{Strengths, limitations and future directions}

Strengths of the current study included the breadth of the participant sample and the inclusion of previously under-researched groups such as national and development workers. This allowed a broad range of views and response groups to be examined. While the diverse population is a strength, it can also be a limitation as it prevents us from making recommendations for specific sub-groups such as workers in particular professions or locations. Another key strength was the qualitative approach, which focused on the views of aid workers, allowing rich insight into their experiences and avoiding 
the constraints associated with pre-selected lists and quantitative scales. Qualitative data analysis was supplemented with quantitative analyses to illuminate differences between sub-groups of aid workers.

Although the qualitative approach allowed us to highlight aid workers' views, a limitation is that respondents may have noted stressors and coping strategies which were currently salient and omitted others that were equally important to them. For example, national workers were significantly less likely to cite social support, but this does not necessarily mean social support is not important to them; it could simply be less salient because they have greater access to social networks. Similarly, while trauma was not a prevalent stressor, it is likely to have long-lasting impacts beyond more common stressors such as workload. This is a limitation of qualitative approaches and future research could use mixed method approaches to assess both the prevalence and impact of stressors and coping strategies.

The current study was also limited by its online, English format. The online survey elicited very short responses and future research could use in-depth interviews to add richer information on this topic. The survey was also only available in English which limits the inclusion of the experiences of non-English speakers. This is a common limitation of such surveys and could be rectified in future research by providing the survey in multiple languages.

\section{Conclusion}

The current study is the first to use qualitative research to capture the views of aid workers regarding their key stressors and coping strategies. This approach offers an extensive and nuanced view of aid workers' experiences. Thematic analysis revealed that aid workers face a wide range of stressors which they attempt to manage with numerous coping strategies. Four overarching themes emerged. The most frequently reported stressors were linked to the Work theme. The most commonly mentioned coping strategies were tied to the Lifestyle, Psychological and Social Connection themes. The study results can be used to normalise stress in the sector and provide helpful information on the array of coping strategies used by aid workers. The results can also inform organisational support around workload, and internal communications. At the sector level, we have recommended that donors place more emphasis on aid worker stress and that staff care organisations provide interventions targeting stressors by building psychological flexibility skills. Given that the present coping data mapped onto the psychological flexibility framework which is trans-diagnostic and has broad applicability, ACT informed interventions at the individual, organisational and sector levels are likely to provide the enhancement of human resources in the field. At its core, this study has provided a platform to share aid workers' views on their stressors and coping strategies. It is important that approaches to addressing aid worker stress should take account of the views of the population to provide effective and relevant support for the aid workers, which is likely to have substantial benefits for aid workers and aid delivery.

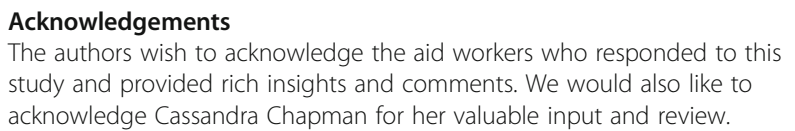

\section{Funding}

The first author is supported by an Australian Government Research Training Program Scholarship. None of the authors received financial support for this article. The study received ethical clearance from the School of Psychology, University of Queensland (17-PSYCH-PHD-36-AH).

Availability of data and materials

The dataset supporting the conclusions of this article is available upon request to the corresponding author.

\section{Authors' contributions}

TY and KP conceived of the study and drafted the survey. TY designed the survey, recruited participants, carried out data collection, and undertook analysis. MN acted as second coder in the analysis process and helped develop codes and themes. TY drafted the paper, while KP and MN both provided contributions within several iterations. All authors read and approved the final manuscript.

Ethics approval and consent to participate

This study was approved by The University of Queensland, School of Psychology Ethics Committee.

\section{Competing interests}

The authors declare that they have no competing interests.

\section{Publisher's Note}

Springer Nature remains neutral with regard to jurisdictional claims in published maps and institutional affiliations.

\section{Author details}

${ }^{1}$ School of Psychology, The University of Queensland, St Lucia, QLD 4072 , Australia. ${ }^{2}$ The Hopkins Centre, Menzies Health Institute Queensland, Griffith University, Meadowbrook, Australia.

Received: 7 June 2018 Accepted: 11 October 2018

Published online: 14 December 2018

\section{References}

Ager A, lacovou M (2014) The co-construction of medical humanitarianism: analysis of personal, organizationally condoned narratives from an agency website. Soc Sci Med 120:430-438. https://doi.org/10.1016/j.socscimed.2014.05.053.

Ager A, Pasha E, Yu G, Duke T, Eriksson CB, Cardozo BL (2012) Stress, mental health, and burnout in national humanitarian aid workers in Gulu, northern Uganda. J Trauma Stress 25(6):713-720. https://doi.org/10.1002/jts.21764.

Alonso JA, Glennie J (2015) What is development cooperation. United Nations Economic and Social Council (ECOSOC): New York.

Blanchetiere P (2006) Resilience of humanitarian workers. Retrieved February, 8, 2008,

Bond FW, Bunce D (2000) Mediators of change in emotion-focused and problem-focused worksite stress management interventions. J Occup Health Psychol 5(1):156

Boyatzis RE (1998) Transforming qualitative information: thematic analysis and code development. Sage, Thousand Oaks.

Braun V, Clarke V (2012) Thematic analysis. APA Handb Res Methods Psychol 2:57-71. 
Cardozo BL \& Salama P (2002) Mental health of humanitarian aid workers in complex emergencies.

Clarke P \& Ramalingam B (2008) Organisational change in the humanitarian sector. ALNAP Seventh Review of Humanitarian Action.

Comoretto A, Crichton N, Albery I (2015) Resilience in humanitarian aid workers: understanding processes of development. IIE Trans Occup Ergon Hum Factors 3(3-4):197-209.

Connorton E, Perry MJ, Hemenway D, Miller M (2012) Humanitarian relief workers and trauma-related mental illness. Epidemiol Rev 34:145-155. https://doi.org/ 10.1093/epirev/mxr026.

Costa M, Oberholzer-Riss M, Hatz C, Steffen R, Puhan M, Schlagenhauf P (2015) Pre-travel health advice guidelines for humanitarian workers: a systematic review. Travel Med Infect Dis 13(6):449-465.

Crane MF, Louis WR, Phillips JK, Amiot CE, Steffens NK (2018) Identity centrality moderates the relationship between acceptance of group-based stressors and well-being. Eur J Soc Psychol 48(6):866-882. https://onlinelibrary.wiley. com/doi/abs/10.1002/ejsp.2367.

Cunningham T, Sesay A (2017) The triple menace in volunteer international aid work: three harmful pitfalls. J Emerg Nurs 43(5):478-481.

Curling P, Simmons KB (2010) Stress and staff support strategies for international aid work. Intervention 8(2):93-105.

Daniels WR (1990) Group power II: a manager's guide to conducting regular meetings. Pfeiffer, San Diego.

Dedoose Version 8.0.35 (2018) Retrieved from https://app.dedoose.com/App/ ?Version=8.0.35. Accessed Jan 2018 .

DeLongis A, Holtzman S (2005) Coping in context: the role of stress, social support, and personality in coping. J Pers 73(6):1633-1656

Dyer WG (2007) Team building: Wiley Online Library.

Ehrenreich JH, Elliott TL (2004) Managing stress in humanitarian aid workers: a survey of humanitarian aid agencies' psychosocial training and support of staff. Peace Conflict 10(1):53.

Eriksson CB, Bjorck JP, Larson LC, Walling SM, Trice GA, Fawcett J et al (2009) Social support, organisational support, and religious support in relation to burnout in expatriate humanitarian aid workers. Ment Health Relig Cult 12(7): 671-686. https://doi.org/10.1080/13674670903029146.

Eriksson CB, Cardozo BL, Foy DW, Sabin M, Ager A, Snider L et al (2012) Predeployment mental health and trauma exposure of expatriate humanitarian aid workers: risk and resilience factors. Traumatology. https:// doi.org/10.1177/1534765612441978.

Farrington A (1995) Suicide and psychological debriefing. Br J Nurs 4(4):209-211.

Fawcett J (2003) Stress and trauma handbook. World Vision International, Monrovia.

Fechter A-M (2012) 'Living well' while 'doing good'? (missing) debates on altruism and professionalism in aid work. Third World Q 33(8):1475-1491. https://doi.org/10.1080/09700161.2012.698133.

Fereday J, Muir-Cochrane E (2006) Demonstrating rigor using thematic analysis: a hybrid approach of inductive and deductive coding and theme development. Int J Qual Methods 5(1):80-92.

Fledderus M, Bohlmeijer E, Pieterse M, Schreurs K (2012) Acceptance and commitment therapy as guided self-help for psychological distress and positive mental health: a randomized controlled trial. Psychol Med 42(03):485-495.

Gritti A (2015) Building aid workers' resilience: why a gendered approach is needed. Gend Dev 23(3):449-462. https://doi.org/10.1080/13552074.2015. 1095542.

Hayes SC, Bissett R, Roget N, Padilla M, Kohlenberg BS, Fisher G et al (2004) The impact of acceptance and commitment training and multicultural training on the stigmatizing attitudes and professional burnout of substance abuse counselors. Behav Ther 35(4):821-835.

Hayes SC, Hofmann SG (2017) The third wave of cognitive behavioral therapy and the rise of process-based care. World Psychiatry 16(3):245-246.

Hayes SC, Luoma JB, Bond FW, Masuda A, Lillis J (2006) Acceptance and commitment therapy: model, processes and outcomes. Behav Res Ther 44(1):1-25.

Hayes SC, Strosahl KD, Wilson KG (2011) Acceptance and commitment therapy: The process and practice of mindful change. Guilford Press. pp. 402

Holtz TH, Salama P, Cardozo BL, Gotway CA (2002) Mental health status of human rights workers, Kosovo, June 2000. J Trauma Stress 15(5):389-395.

Lazarus RS, Folkman S (1984) Coping and adaptation, The handbook of behavioral medicine, pp 282-325.

Lopes Cardozo B, Gotway Crawford C, Eriksson CB, Zhu J, Sabin M, Ager A et al (2012) Psychological distress, depression, anxiety, and burnout among international humanitarian aid workers: a longitudinal study. PLoS One 7(9): e44948. https://doi.org/10.1371/journal.pone.0044948.

Lopes Cardozo B, Sivilli TI, Crawford C, Scholte WF, Petit P, Ghitis F et al (2013) Factors affecting mental health of local staff working in the Vanni region, Sri Lanka. Psychol Trauma Theory Res Pract Policy 5(6):581-590. https://doi.org/ 10.1037/a0030969.

Luoma JB, Hayes SC, Walser RD (2007) Learning ACT: an acceptance \& commitment therapy skills-training manual for therapists. New Harbinger Publications, Oakland

Maudsley G (2011) Mixing it but not mixed-up: mixed methods research in medical education (a critical narrative review). Med Teach 33(2):e92-e104.

McKay L (2007) Understanding and coping with stress; online training module one. Headington Institute, Pasadena.

McKay L (2011) Resilience. Building resilient managers in humanitarian organizations: strengthening key organizational structures and personal skills that promote resilience in challenging environments. People in Aid, London.

Monat A, Lazarus RS (1991) Stress and coping: an anthology. Columbia University Press, New York.

Pigni A (2014) Building resilience and preventing burnout among aid workers in Palestine: a personal account of mindfulness based staff care. Intervention 12(2):231-239.

Pines AM, Keinan G (2005) Stress and burnout: the significant difference. Personal Individ Differ 39(3):625-635.

Porter B, Emmens B (2009) Approaches to staff care in international NGOs. People in Aid and InterHealth, London.

Powers MB, Zum Vörde Sive Vörding MB, Emmelkamp PM (2009) Acceptance and commitment therapy: a meta-analytic review. Psychother Psychosom 78(2):73-80.

Punch KF (2013) Introduction to social research: Quantitative and qualitative approaches. SAGE Publications Ltd, London.

Qualtrics (2017) Qualtrics. Retrieved from http://www.qualtrics.com.

Shah SA, Garland E, Katz C (2007) Secondary traumatic stress: prevalence in humanitarian aid workers in India. Traumatology 13(1):59.

Skeoch K, Stevens GJ, Taylor M (2017) Future role aspirations, achievement motivations and perceptions of personal help-seeking among humanitarian aid trainees. J Int Humanit Action 2(1):12.

Stoddard A, Harmer A, DiDomenico V (2009) Providing aid in insecure environments: 2009 update. HPG Policy Brief 34(10). https://www.odi.org/ resources/docs/4243.pdf.

Taylor G, Stoddard A, Harmer A, Haver K, Harvey P, Barber K et al (2012) The state of the humanitarian system. Overseas Development Institute/ALNAP, London.

Webster M, Walker P (2009) One for all and all for one: intra-organizational dynamics in humanitarian action. Feinstein International Center, Medford.

\section{Submit your manuscript to a SpringerOpen ${ }^{\circ}$ journal and benefit from:}

- Convenient online submission

- Rigorous peer review

- Open access: articles freely available online

High visibility within the field

- Retaining the copyright to your article

Submit your next manuscript at $>$ springeropen.com 